\title{
PENGARUH DOSIS PAKLOBUTRAZOL TERHADAP PERTUMBUHAN DAN PRODUKSI BUNGA MATAHARI (Helianthus annuus L.)
}

\author{
Laras Ayu Kinasih* dan Elfarisna \\ Fakultas Pertanian Universitas Muhammadiyah Jakarta \\ Jl. K.H. Ahmad Dahlan Cirendeu Ciputat Tangerang Selatan 15419 \\ *E-mail: larasknsh@gmail.com
}

\begin{abstract}
ABSTRAK
Tanaman bunga matahari pada umumnya masih dibudidayakan di lahan luas dan masih sedikit yang membudidayakannya dalam pot. Beragamnya jenis bunga matahari yang ditanam membuat orang untuk mengoptimalkan pertumbuhan tanaman tersebut. Salah satunya dengan pemberian zat pengatur tumbuh yaitu Paklobutrazol. Paklobutrazol merupakan jenis retardan yang digunakan untuk mempercepat pembungaan serta menghambat pertumbuhan tanaman. Penelitian bertujuan untuk mendapatkan dosis Paklobutrazol yang tepat untuk menghambat pertumbuhan tanaman bunga matahari. Penelitian dilaksanakan pada bulan Februari sampai Juni 2019 di Jalan Parakan, Pamulang Permai 2, Tangerang Selatan. Penelitian menggunakan Rancangan Kelompok Lengkap Teracak (RKLT) dengan 6 perlakuan dan 4 ulangan, yaitu $\mathrm{P} 0=$ kontrol, $\mathrm{P} 1=50$ $\mathrm{mL} /$ polibag, $\mathrm{P} 2=100 \mathrm{~mL} /$ polibag, $\mathrm{P} 3=150 \mathrm{~mL} /$ polibag, $\mathrm{P} 4=200 \mathrm{~mL} /$ polibag, dan $\mathrm{P} 5$ $=250 \mathrm{~mL} /$ polibag dengan konsentrasi $50 \mathrm{ppm}$. Variabel yang diamati adalah tinggi tanaman, diameter batang, jumlah daun, jumlah ruas, jumlah cabang dan ranting, umur berbunga, diameter bunga primer, jumlah biji dan berat biji. Hasil penelitian dapat disimpulkan : Pemberian Paklobutrazol dengan berbagai dosis memberikan pengaruh yang sangat nyata umur 6 sampai 11 MST pada tinggi tanaman bunga matahari tetapi tidak berpengaruh nyata pada pengamatan lainnya. Perlakuan Paklobutrazol dosis 250 $\mathrm{mL} /$ polibag memberikan pengaruh yang terbaik dalam menekan tinggi tanaman dibandingkan dengan perlakuan kontrol.
\end{abstract}

Kata kunci: Bunga matahari, paklobutrazol, dosis

\section{ABSTRACT}

Sunflower plants in general are still cultivated on vast grounds and still few are cultivating them in pots. The variety of the planted sunflowers makes people to optimize the growth of these crops. One of them with the provision of growing regulatory substances is Paklobutrazol. The liquid paklobutrazole used to accelerate the flowering and inhibit the growth of plants. The research aims for the proper Kokoro Paklobutrazol dosage to inhibit the growth of sunflower plants. Research conducted in February to June 2019 in Parakan Street, Pamulang Permai 2, South Tangerang. The study uses the randomized complete Block design (RCBD) with 6 treatments and 4 replication, i.e. $P 0$ = control, $P 1=50 \mathrm{~mL} /$ polybag, $P 2=100 \mathrm{~mL} /$ polybag, $P 3=150 \mathrm{~mL} /$ polybag, $P 4=200$ $\mathrm{mL} /$ polybag, and P5 $=250 \mathrm{~mL} /$ polybag with a concentration of $50 \mathrm{ppm}$. The observed 
variable is height of the plant, diameter of the stem, number of leaves, number of sections, number of branches and ranting, age of flowering, Diameter of primary flowers, number of seeds and seed weight. The results of the study can be concluded: the administration of paklobutrazole with a variety of doses gives a very noticeable effect of 6 to 11 WAP on high sunflower plants but has no noticeable effect on other observations. Paklobutrazol treatment Dose $250 \mathrm{~mL}$ Polybag gives the best influence in the high pressing of the plant compared to the treatment control.

Keywords: Sunflower, paclobutrazol, doses

\section{PENDAHULUAN}

Bunga matahari (Helianthus annuus L.) adalah tanaman yang indah dipandang dan mudah perawatannya, oleh karena itu tanaman ini telah lama dikenal di Indonesia sebagai tanaman hias. Di Indonesia, kebutuhan akan bunga yang merupakan salah satu produk florikultura cukup mengesankan, salah satunya bunga matahari. Bunga matahari biasanya dimanfaatkan oleh masyarakat sebagai tanaman pagar untuk menghiasi halaman rumahnya. Sedangkan di luar negeri seperti Eropa dan Amerika, tanaman ini dimanfaatkan sebagai bunga potong dan penghasil minyak nabati (Marshel, 2014).

Bunga matahari memiliki nama botani Helianthus annuus L. yang termasuk ke dalam famili Asteraceae ( Saini and Sharma, 2011). Tanaman bunga matahari adalah salah satu tanaman penghasil minyak ke-empat terbesar setelah kepala sawit, kedelai, dan biji kanola. Menurut data FAO tahun 2018, produksi minyak biji bunga matahari mencapai 15,29 juta metrik ton. Tanaman bunga matahari pada dasarnya sangat mudah untuk tumbuh dalam berbagai kondisi. Kemampuan beradaptasi yang tinggi, karena akarnya yang dalam memungkinkan tanaman bunga matahari untuk bertahan, baik dalam kondisi kering maupun basah (National Sunflower Association of Canada, 2011).

Tanaman bunga matahari pada umumnya masih dibudidayakan di lahan luas dan masih sedikit yang membudidayakannya dalam pot sebagai tanaman hias pot, sebab tanaman tumbuh terlalu tinggi dan mudah rebah jika telah berbunga (Widaryanto et al, 2011). Beragamnya jenis bunga matahari yang ditanam membuat banyak orang berusaha mengoptimalkan pertumbuhan tanaman tersebut. Salah satunya dengan cara pemberian zat pengatur tumbuh. Zat pengatur tumbuh yang biasa digunakan adalah Paklobutrazol.

Paklobutrazol secara fisiologis berperan dalam menekan perpanjangan batang karena aktivitas Paklobutrazol yang dapat menghambat biosintesis giberelin (Wahyurini, 2010). Penggunaan Paklobutrazol dengan kata lain dapat menjadi solusi untuk mengatasi potensi kerebahan pada tanaman pot bunga matahari.

Paklobutrazol dapat mendorong pembungaan, mendorong pembentukan pigmen, mencegah etiolasi, dan memperpanjang perakaran stek. Paklobutrazol dalam konsentrasi rendah dapat meningkatkan ketahanan tanaman terhadap penyakit (Novi dan Rizki, 2014).

Sandra (2007), menyatakan efek Paklobutrazol pada pertumbuhan vegetatif adalah memperpendek ruas sehingga menghambat pertumbuhan tinggi tanaman, memperbesar diameter batang tanaman, dan memperbanyak hasil fotosintesis dalam tanaman.

Penelitian yang pernah dilakukan
oleh Nugroho, $\quad$ (2012) yang


mendapatkan hasil bahwa pemberian paklobutrazol $10 \mathrm{ppm}$ dengan dosis 200 $\mathrm{mL} /$ pot dapat mempengaruhi pertumbuhan vegetatif tanaman bunga matahari, terutama terhadap peubah tinggi tanaman. Hasil penelitian lain oleh Suhadi et. al., (2017) menyatakan bahwa penggunaan Paklobutrazol 50 ppm memberikan nilai efektivitas terbaik terhadap tinggi tanaman serta diameter batang bunga matahari varietas giant single pada umur 35 hst dan 42 hst.

Berdasarkan hal tersebut perlu dilakukan penelitian tentang penggunaan Paklobutrazol pada dosis yang berbeda pada tanaman Bunga Matahari. Penelitian ini bertujuan untuk mendapatkan dosis Paklobutrazol yang tepat untuk menghambat pertumbuhan dan produksi tanaman bunga matahari.

\section{METODE}

Penelitian ini dilaksanakan bertempat di Jalan Parakan, Pamulang Permai 2, Tangerang Selatan pada bulan Februari sampai Juni 2019. Lokasi berada di ketinggian $25 \mathrm{~m}$ di atas permukaan laut (dpl) dengan jenis tanah Latosol. Penelitian menggunakan Rancangan Kelompok Lengkap Teracak (RKLT) dengan enam perlakuan dosis Paklobutrazol masing-masing P0 (tanpa Paklobuutrazol (kontrol)), P1 (50 $\mathrm{mL} /$ polibag), P2 (100 mL/polibag), P3 (150 mL/polibag), P4 (200 mL/polibag) dan P5 (250 $\mathrm{mL} /$ polibag) dan empat ulangan. Setiap satuan percobaan terdiri dari 3 tanaman, sehingga jumlah tanaman yang dieliti adalah 72 tanaman.

Benih bunga matahari disemai dalam tray semai berisi media tanam tanah dan pupuk kandang 1:1 yang telah dicampurkan. Penyemaian berlangsung selama dua minggu baru dipindahkan ke media tanam. Media tanam berupa campuran tanah dan pupuk kandang dengan perbandingan 1:2 (Ilham, 2018). Media tanam kemudian dimasukkan ke dalam polibag berukuran $40 \times 40 \mathrm{~cm}$ sebanyak $10 \mathrm{~kg}$. Bibit bunga matahari yang telah berumur dua minggu dipindahkan ke dalam media tanam polibag dengan membuat lubang tanam sedalam 2,5 - $5 \mathrm{~cm}$. Pemberian Paklobutrazol dilakukan pada umur 2 MST hingga 5 MST. Paklobutrazol yang digunakan adalah ZPT Paklobutrazol Patrol dengan konsentrasi 50 ppm yang disiramkan ke media tanam (soil drenching). Penyiraman dilakukan setiap hari, setiap pagi dan sore hari. Pemupukan dilakukan pada saat umur 3 MST menggunakan pupuk majemuk Mutiara 16-16-16 dengan dosis 2 g/polibag (Nugroho, 2012). Pengendalian hama dan penyakit dilakukan secara manual yakni dengan cara disemprotkan menggunakan sprayer ke bagian tanaman yang terkena hama dan penyakit. Insektisida yang digunakan insektisida Decis ${ }^{\circledR}$ 25EC. Panen dilakukan pada saat tanaman sudah tua yang ditandai dengan mengeringnya kelopak bunga. Pemanenan dilakukan pada umur 108 HST, lalu bunga yang telah dipanen dikeringkan selama satu minggu.

Pengamatan dilakukan setiap minggu dimulai 6 MST hingga panen. Parameter yang diamati adalah tinggi tanaman, diameter batang, jumlah daun, jumlah ruas, jumlah cabang dan ranting, umur berbunga, diameter bunga primer, jumlah biji dan berat biji.

\section{HASIL DAN PEMBAHASAN}

Kondisi iklim pada saat penelitian dapat dilihat pada Tabel 1. Kondisi cuaca telah memenuhi syarat dengan kelembaban udara 70 - $90 \%$ dan suhu $15-30{ }^{\circ} \mathrm{C}$ (Dinas Pertanian Pangan, 2014) kecuali curah hujan dari bulan Februari sampai Mei. Selama penelitian, pertumbuhan bunga matahari berlangsung dengan sangat baik dan tidak ditemukannya tanaman yang tumbuh abnormal. Tetapi dengan curah hujan yang tinggi pada bulan Februari sampai Mei tanaman terserang penyakit yang merusak daun, meskipun daunnya 
tidak gugur. Pada umur 3 MST tanaman mulai terserang hama yang mengakibatkan daun menjadi rusak dan bolong-bolong. Selain itu, saat tanaman bunga matahari sudah cukup banyak daun, hama yang menyerang mulai bertambah yang berakibat daun pada tanaman menjadi rusak dan bolong.

Tabel 1. Data Iklim Bulan Februari - Juni 2019

\begin{tabular}{ccccccc}
\hline \multirow{3}{*}{ Bulan } & \multicolumn{2}{c}{ Total } & \multicolumn{3}{c}{ Rata-Rata } & Arah \\
\cline { 2 - 6 } & $\begin{array}{c}\text { Curah } \\
\text { Hujan } \\
(\mathrm{mm})\end{array}$ & $\begin{array}{c}\text { Intensitas } \\
\text { Penyinaran } \\
(\%)\end{array}$ & $\begin{array}{c}\text { Kelembaban } \\
(\%)\end{array}$ & $\begin{array}{c}\text { Suhu } \\
\text { Udara } \\
\left({ }^{\circ} \mathrm{C}\right)\end{array}$ & $\begin{array}{c}\text { Kecepatan } \\
\text { Angin } \\
(\mathrm{km} / \text { jam })\end{array}$ & $\begin{array}{c}\text { Angin } \\
\left({ }^{\circ}\right)\end{array}$ \\
\hline Februari & 146 & 53 & 83 & 27,8 & 8 & 270 \\
\hline Maret & 141 & 42 & 82 & 27,5 & 9 & 260 \\
\hline April & 261 & 62 & 82 & 28,1 & 9 & 260 \\
\hline Mei & 159 & 71 & 77 & 28,7 & 9 & 80 \\
\hline Juni & 71 & 61 & 74 & 28,3 & 7 & 90 \\
\hline
\end{tabular}

Sumber : Badan Meteorologi, Klimatologi dan Geofisika Pondok Betung - Tangerang Selatan, 2019

\section{Tinggi Tanaman}

Pemberian dosis Paklobutrazol berpengaruh sangat nyata terhadap hasil pengamatan tinggi tanaman. Pada umur 6 - 11 MST pemberian Paklobutrazol dosis $250 \mathrm{~mL} /$ polybag mampu memperpendek tinggi tanaman. Hal ini mampu menekan tinggi tanaman Bunga Matahari.

Santiasrini (2009) mengemukakan bahwa pemberian Paklobutrazol dengan konsentrasi yang semakin tinggi akan menyebabkan tinggi tanaman semakin rendah. Dengan demikian tanaman yang diberi Paklobutrazol diduga lebih rendah dibandingkan dengan perlakuan tanpa Paklobutrazol. Giberelin dalam tanaman antara lain berperan dalam pemanjangan sel yang akan menentukan tinggi tanaman (Suhadi et., al., 2017). Hal ini sejalan dengan pendapat Rani (2006) yang menyatakan bahwa aplikasi Paklobutrazol menekan pertumbuhan tinggi tanaman bunga matahari kultivar Hallo dan Teddy Bear dengan menghambat perpanjangan ruas tanaman. Aplikasi Paklobutrazol lebih efektif diberikan saat tanaman masih muda atau semakin awal diberikan maka semakin besar sifat penghambatnya (Widaryanto et. al., 2011).

Tabel. 2 Pengaruh Dosis Paklobutrazol terhadap Tinggi Tanaman Bunga Matahari padaUmur 6 MST sampai 11 MST.

\begin{tabular}{ccccccc}
\hline Perlakuan & \multicolumn{5}{c}{ Tinggi Tanaman $(\mathrm{cm})$} \\
\cline { 2 - 7 } Paklobutrazol & $6 \mathrm{MST}$ & $7 \mathrm{MST}$ & $8 \mathrm{MST}$ & $9 \mathrm{MST}$ & $10 \mathrm{MST}$ & $11 \mathrm{MST}$ \\
\hline $0 \mathrm{~mL} /$ polibag & $91,60 \mathrm{~d}$ & $125,33 \mathrm{c}$ & $152,75 \mathrm{c}$ & $190,25 \mathrm{c}$ & $199,17 \mathrm{~b}$ & $200,00 \mathrm{~b}$ \\
\hline $50 \mathrm{~mL} /$ polibag & $81,50 \mathrm{~cd}$ & $116,08 \mathrm{bc}$ & $142,33 \mathrm{bc}$ & $182,75 \mathrm{bc}$ & $191,25 \mathrm{ab}$ & $193,50 \mathrm{ab}$ \\
\hline $100 \mathrm{~mL} /$ polibag & $79,50 \mathrm{bc}$ & $114,42 \mathrm{bc}$ & $141,33 \mathrm{bc}$ & $180,67 \mathrm{bc}$ & $188,42 \mathrm{ab}$ & $189,42 \mathrm{ab}$ \\
\hline $150 \mathrm{~mL} /$ polibag & $68,50 \mathrm{ab}$ & $104,83 \mathrm{ab}$ & $129,58 \mathrm{ab}$ & $169,00 \mathrm{ab}$ & $177,50 \mathrm{a}$ & $180,50 \mathrm{a}$ \\
\hline $200 \mathrm{~mL} /$ polibag & $67,75 \mathrm{a}$ & $105,50 \mathrm{ab}$ & $131,58 \mathrm{ab}$ & $173,41 \mathrm{ab}$ & $182,92 \mathrm{ab}$ & $184,17 \mathrm{ab}$ \\
\hline $250 \mathrm{~mL} /$ polibag & $\mathbf{6 2 , 5 0} \mathbf{a}$ & $\mathbf{9 5 , 4 2} \mathbf{a}$ & $\mathbf{1 1 9 , 8 3} \mathbf{a}$ & $\mathbf{1 6 2 , 3 3} \mathbf{a}$ & $\mathbf{1 7 4 , 2 5} \mathbf{a}$ & $\mathbf{1 7 7 , 0 0} \mathbf{a}$ \\
\hline
\end{tabular}

Keterangan: Angka-angka yang diikuti huruf yang sama pada kolom yang sama tidak berbeda nyata berdasarkan uji BNJ pada taraf $5 \%$

\section{Diameter Batang}

Pada umur 6 MST dan 10 MST merupakan perlakuan yang menghasilkan diameter batang terbaik $16,89 \mathrm{~mm}$ dan $30,90 \mathrm{~mm}$ pada perlakuan dosis $250 \mathrm{~mL} /$ polibag tetapi tidak 
berbeda nyata dengan perlakuan lainnya (Tabel 3.).

Widaryanto et. al. (2011) melaporkan bahwa penambahan Paklobutrazol dapat menekan pertumbuhan batang tanaman sehingga diameter batang bertambah tebal. Penebalan ini disebabkan oleh terjadinya peningkatan volume sel parenkim di daerah korteks yang dapat meningkatkan produksi sel di daerah kambium sehingga diameter batang bertambah tebal. Hasil data di bawah sesuai dengan hasil penelitian yang diperoleh oleh Rani (2006), yang menyatakan bahwa tanaman matahari yang diberikan Paklobutrazol memiliki diameter batang yang 0,9- 9,6 $\mathrm{mm}$ lebih besar dibandingkan tanaman yang tidak diberikan perlakuan Paklobutrazol.

Tabel. 3 Pengaruh Dosis Paklobutrazol terhadap Diameter Batang Tanaman Bunga Matahari pada Umur 6 MST sampai 11 MST.

\begin{tabular}{|c|c|c|c|c|c|c|}
\hline \multirow{2}{*}{$\begin{array}{c}\text { Perlakuan } \\
\text { Paklobutrazol }\end{array}$} & \multicolumn{6}{|c|}{ Diameter Batang (mm) } \\
\hline & $6 \mathrm{MST}$ & $7 \mathrm{MST}$ & $8 \mathrm{MST}$ & $9 \mathrm{MST}$ & $10 \mathrm{MST}$ & $11 \mathrm{MST}$ \\
\hline $0 \mathrm{~mL} /$ polibag & $15,43 \mathrm{a}$ & $24,84 \mathrm{a}$ & $27,16 \mathrm{a}$ & $28,79 \mathrm{a}$ & $30,09 \mathrm{a}$ & $31,21 \mathrm{a}$ \\
\hline $50 \mathrm{~mL} /$ polibag & $15,61 \mathrm{a}$ & $24,68 \mathrm{a}$ & $26,49 a$ & $27,94 \mathrm{a}$ & $29,97 \mathrm{a}$ & $30,98 \mathrm{a}$ \\
\hline $100 \mathrm{~mL} /$ polibag & $16,21 \mathrm{a}$ & $26,29 \mathrm{a}$ & $27,48 \mathrm{a}$ & $28,86 \mathrm{a}$ & $30,14 \mathrm{a}$ & $31,88 \mathrm{a}$ \\
\hline $150 \mathrm{~mL} /$ polibag & $16,70 \mathrm{a}$ & $25,93 \mathrm{a}$ & $26,6 \mathrm{a}$ & $28,17 \mathrm{a}$ & $30,21 \mathrm{a}$ & $32,22 \mathrm{a}$ \\
\hline $200 \mathrm{~mL} /$ polibag & $16,68 \mathrm{a}$ & 26,61 a & 28,00 a & 29,49 a & $30,57 \mathrm{a}$ & 32,51 a \\
\hline $250 \mathrm{~mL} /$ polibag & 16,89 a & $26,29 \mathrm{a}$ & $26,51 \mathrm{a}$ & $28,05 \mathrm{a}$ & 30,90 a & $32,16 \mathrm{a}$ \\
\hline
\end{tabular}

Keterangan: Angka-angka yang diikuti huruf yang sama pada kolom yang sama tidak berbeda nyata berdasarkan uji BNJ pada taraf 5\%

Pada saat umur 7 MST sampai 9 MST dan 11 MST pada perlakuan dosis $200 \mathrm{~mL} /$ polibag memberikan diameter yang besar tetapi tidak berbeda nyata dengan perlakuan lainnya. Pada umur 11 MST perlakuan dosis $200 \mathrm{~mL} /$ polybag menghasilkan diameter batang sebesar 32,51 mm (Tabel 3.).

Paklobutrazol dengan dosis 200 $\mathrm{mL} /$ polibag efektif mampu menambah atau mempertebal ukuran diameter batang dibandingkan dengan tanaman yang tidak diaplikasikan Paklobutrazol, meskipun hasil uji lanjut menyatakan tidak berbeda nyata.

\section{Jumlah Daun}

Pada saat 8 MST perlakuan Paklobutrazol dengan dosis 150 $\mathrm{mL} /$ polibag memberikan perbedaan yang tidak nyata tehadap jumlah daun. Pada saat umur 9 MST sampai 11 MST
Paklobutrazol dengan dosis 100 $\mathrm{mL} /$ polibag memberikan perbedaan yang tidak nyata pada jumlah daun. Hal ini disebabkan karena Paklobutrazol merupakan retardan yang dapat menghambat biosintesis giberelin dan menghambat pemanjangan sel meristem sub apikal pada batang tanaman sehingga tidak mempengaruhi jumlah daun karena pertumbuhan daun terletak pada meristem apikal.

Namun pada umur 9 MST sampai 11 MST terjadi penurunan jumlah daun disebabkan suhu udara yang meningkat sehingga terjadi penguapan yang mengakibatkan daun menjadi layu dan kering (Tabel 4). Selain karena kering dan gugur, penurunan jumlah daun pada tanaman bunga matahari juga terserang hama dengan gejala terdapat serbuk putih pada permukaan daun menjadi rusak dan menjadi gugur. 
Tabel. 4 Pengaruh Dosis Paklobutrazol terhadap Jumlah Daun Tanaman Bunga Matahari pada Umur 6 MST sampai 11 MST.

\begin{tabular}{ccccccc}
\hline Perlakuan & \multicolumn{7}{c}{ Jumlah Daun (helai) } \\
\cline { 2 - 7 } Paklobutrazol & $6 \mathrm{MST}$ & $7 \mathrm{MST}$ & $8 \mathrm{MST}$ & $9 \mathrm{MST}$ & $10 \mathrm{MST}$ & $11 \mathrm{MST}$ \\
\hline $0 \mathrm{~mL} /$ polibag & $44,58 \mathrm{a}$ & $61,50 \mathrm{a}$ & 71,08 a & $89,25 \mathrm{a}$ & $87,16 \mathrm{a}$ & $85,17 \mathrm{a}$ \\
\hline $50 \mathrm{~mL} /$ polibag & $47,50 \mathrm{a}$ & $56,08 \mathrm{a}$ & $66,50 \mathrm{a}$ & $83,25 \mathrm{a}$ & $81,50 \mathrm{a}$ & $79,75 \mathrm{a}$ \\
\hline $100 \mathrm{~mL} /$ polibag & $\mathbf{4 8 , 2 5}$ a & $\mathbf{6 3 , 5 8}$ a & $73,08 \mathrm{a}$ & $\mathbf{8 9 , 8 3}$ a & $\mathbf{8 9 , 7 5}$ a & $\mathbf{8 8 , 2 5}$ a \\
\hline $150 \mathrm{~mL} /$ polibag & $46,75 \mathrm{a}$ & $61,00 \mathrm{a}$ & $\mathbf{7 3 , 3 3}$ a & $86,25 \mathrm{a}$ & $86,33 \mathrm{a}$ & $84,33 \mathrm{a}$ \\
\hline $200 \mathrm{~mL} /$ polibag & $42,25 \mathrm{a}$ & $56,41 \mathrm{a}$ & $67,16 \mathrm{a}$ & $74,83 \mathrm{a}$ & $78,83 \mathrm{a}$ & $77,33 \mathrm{a}$ \\
\hline $250 \mathrm{~mL} /$ polibag & $44,16 \mathrm{a}$ & $61,08 \mathrm{a}$ & $67,75 \mathrm{a}$ & $84,50 \mathrm{a}$ & $84,41 \mathrm{a}$ & $82,67 \mathrm{a}$ \\
\hline
\end{tabular}

Keterangan: Angka-angka yang diikuti huruf yang sama pada kolom yang sama tidak berbeda nyata berdasarkan uji BNJ pada taraf 5\%

\section{Jumlah Ruas}

Pada umur 9 MST perlakuan penyiraman Paklobutrazol kontrol dan dosis $50 \mathrm{ml} /$ polibag setelah diuji lanjut BNJ taraf 5\% memberikan hasil jumlah ruas terbanyak tetapi tidak berbeda nyata dengan perlakuan lainnya. Pada umur 10 MST memberikan hasil jumlah ruas terbanyak 31,67 pada perlakuan kontrol dan Paklobutrazol $200 \mathrm{ml} /$ polibag tidak berbeda nyata dengan perlakuan lainnya.

Pada umur 6 MST sampai 9 MST dan 11 MST perlakuan dosis
Paklobutrazol $50 \quad \mathrm{ml} /$ polibag memberikan hasil jumlah ruas yang tidak berbeda nyata. Hal tersebut dikarenakan senyawa Paklobutrazol hanya mempengaruhi ukuran ruas bukan jumlah ruas pada tanaman yang disebabkan oleh penurunan laju pembelahan sel pada batang yang dipicu oleh senyawa tersebut (Marshel, 2014). Pendapat yang sama juga dinyatakan Sandra (2007), yang menyatakan bahwa efek Paklobutrazol pada pertumbuhan vegetatif adalah memperpendek ruas sehingga menghambat pertumbuhan tinggi tanaman.

Tabel. 5 Pengaruh Dosis Paklobutrazol terhadap Jumlah Ruas Bunga Matahari pada Umur 6 MST sampai 11 MST.

\begin{tabular}{ccccccc}
\hline Perlakuan & \multicolumn{7}{c}{ Jumlah Ruas (buah) } \\
\cline { 2 - 7 } Paklobutrazol & $6 \mathrm{MST}$ & $7 \mathrm{MST}$ & $8 \mathrm{MST}$ & $9 \mathrm{MST}$ & $10 \mathrm{MST}$ & $11 \mathrm{MST}$ \\
\hline $0 \mathrm{~mL} /$ polibag & 19,83 a & 24,33 a & 27,00 a & $\mathbf{2 9 , 6 7}$ a & $\mathbf{3 1 , 6 7}$ a & 32,33 a \\
\hline $50 \mathrm{~mL} /$ polibag & $\mathbf{2 0 , 1 7}$ a & $\mathbf{2 4 , 8 3}$ a & $\mathbf{2 7 , 1 6}$ a & $\mathbf{2 9 , 6 7}$ a & 31,16 a & $\mathbf{3 2 , 4 1}$ a \\
\hline $100 \mathrm{~mL} /$ polibag & 20,08 a & 23,58 a & 26,75 a & 29,25 a & 31,08 a & 32,17 a \\
\hline $150 \mathrm{~mL} /$ polibag & 19,91 a & 23,67 a & 26,41 a & 28,83 a & 30,25 a & 31,25 a \\
\hline $200 \mathrm{~mL} /$ polibag & 19,16 a & 24,25 a & 26,16 a & 29,25 a & $\mathbf{3 1 , 6 7}$ a & 31,67 a \\
\hline $250 \mathrm{~mL} /$ polibag & 18,41 a & 22,58 a & 25,08 a & 28,41 a & 31,00 a & 31,33 a \\
\hline
\end{tabular}

Keterangan: Angka-angka yang diikuti huruf yang sama pada kolom yang sama tidak berbeda nyata berdasarkan uji BNJ pada taraf $5 \%$

\section{Jumlah Cabang dan Ranting}

Pemberian Paklobutrazol tidak berpengaruh pada jumlah cabang dan ranting tanaman bunga matahari. Pada umur 6 MST perlakuan Paklobutrazol $100 \mathrm{ml} /$ polibag menghasilkan jumlah cabang dan ranting terbanyak tetapi tidak berbeda nyata denggan perlakuan lainnya.
Saat umur 7, 10, dan 11 MST jumlah cabang terbanyak terdapat pada perlakuan Paklobutrazol $150 \mathrm{ml} /$ polibag yakni 25,$33 ; 40,83$ dan 41,08 buah namun tidak berbeda nyata dengan perlakuan lainnya.

Pada umur 8 MST sampai 9 MST menunjukkan hasil cabang terbanyak yakni 27,25 dan 38,25 buah pada 
perlakuan dosis $100 \mathrm{ml} /$ polibag tidak berbeda nyata dengan perlakuan lainnya.

Data yang tersaji pada Tabel 6., 6 11 MST mengalami peningkatan jumlah cabang dan ranting bunga matahari. Hal ini disebabkan penghambatan pertumbuhan yang diakibatkan oleh aplikasi paklobutrazol muncul karena komponen kimia yang terkandung dalam paklobutrazol menghalangi tiga tahapan untuk produksi giberelin pada jalur terpenoid dengan cara menghambat enzim yang mengkatalisasi proses reaksi metabolis. Salah satu fungsi utama dari giberelin adalah untuk menstimulasi perpanjangan sel. Ketika produksi giberelin dihambat, pembelahan sel tetap terjadi namun sel-sel baru tidak mengalami pemanjangan. Hasilnya adalah terbentuknya cabang dengan panjang ruas lebih pendek (Chaney, 2004).

Tabel. 6 Pengaruh Dosis Paklobutrazol terhadap Jumlah Cabang dan Ranting Bunga Matahari pada Umur 6 MST sampai 11 MST.

\begin{tabular}{lllllll}
\hline \multirow{2}{*}{$\begin{array}{c}\text { Perlakuan } \\
\text { Paklobutrazol }\end{array}$} & \multicolumn{7}{c}{ Jumlah Cabang dan Ranting (buah) } \\
\cline { 2 - 7 } $0 \mathrm{~mL} /$ polibag & 18,08 a & 24,92 a & 27,08 a & 36,75 a & 39,50 a & 39,41 a \\
\hline $50 \mathrm{~mL} /$ polibag & 19,75 a & 25,25 a & 26,83 a & 35,66 a & 39,08 a & 39,91 a \\
\hline $100 \mathrm{~mL} /$ polibag & $\mathbf{1 9 , 8 3}$ a & 24,92 a & $\mathbf{2 7 , 2 5}$ a & $\mathbf{3 8 , 2 5}$ a & 39,75 a & 40,16 a \\
\hline $150 \mathrm{~mL} /$ polibag & 18,66 a & $\mathbf{2 5 , 3 3}$ a & 27,08 a & 37,08 a & $\mathbf{4 0 , 8 3}$ a & $\mathbf{4 1 , 0 8 ~ a}$ \\
\hline $200 \mathrm{~mL} /$ polibag & 18,08 a & 24,42 a & 26,58 a & 37,00 a & 38,58 a & 40,25 a \\
\hline $250 \mathrm{~mL} /$ polibag & 18,41 a & 24,92 a & 26,08 a & 35,66 a & 39,83 a & 40,91 a \\
\hline
\end{tabular}

Keterangan: Angka-angka yang diikuti huruf yang sama pada kolom yang sama tidak berbeda nyata berdasarkan uji BNJ pada taraf 5\%

\section{Umur Berbunga}

Umur berbunga tercepat terdapat pada perlakuan kontrol (tanpa Paklobutrazol) 75,17 HST tetapi tidak berbeda nyata dengan perlakuan lainnya (Tabel 7.). Hal ini dikarenakan Paklobutrazol lebih berpengaruh pada pemendekan batang dibandingkan organ vegetatif lainnya. Menurut Samanhudi (2006), kandungan gula di dalam tanaman juga berperan dalam menstimulasi suatu gen pengontrol waktu pembungaan yang disebut leafly dan berperan sebagai inducer (penginduksi) dari pembungaan. Pengaruh retardan terhadap pembungaan merupakan pengaruh sekunder sedangkan pengaruh primernya adalah penekanan pertumbuhan vegetatif (Nugroho, 2012).
Tabel. 7 Pengaruh Dosis Paklobutrazol terhadap Umur Berbunga Tanaman Bunga Matahari.

\begin{tabular}{lc}
$\begin{array}{c}\text { Perlakuan } \\
\text { Paklobutrazol }\end{array}$ & $\begin{array}{c}\text { Umur Berbunga } \\
\text { (hst) }\end{array}$ \\
\hline $0 \mathrm{~mL} /$ polibag & $\mathbf{7 5 , 1 7}$ a \\
\hline $50 \mathrm{~mL} /$ polibag & $75,75 \mathrm{a}$ \\
\hline $100 \mathrm{~mL} /$ polibag & $76,25 \mathrm{a}$ \\
\hline $150 \mathrm{~mL} /$ polibag & $76,50 \mathrm{a}$ \\
\hline $200 \mathrm{~mL} /$ polibag & $77,00 \mathrm{a}$ \\
\hline $250 \mathrm{~mL} /$ polibag & $77,42 \mathrm{a}$ \\
\hline Keterangan: Angka-angka yang diikuti \\
huruf yang & $\begin{array}{l}\text { sama pada } \\
\text { kolom yang sama tidak } \\
\text { berbeda nyata berdasarkan } \\
\text { uji BNJ pada taraf } 5 \%\end{array}$
\end{tabular}

\section{Diameter Bunga Primer}

Diameter bunga terbesar terdapat pada perlakuan dosis $150 \mathrm{~mL} /$ polibag $19,13 \mathrm{~cm}$ tetapi tidak berbeda nyata dengan perlakuan lainnya (Tabel 8). Hal ini dikarenakan pemberian senyawa Paklobutrazol hanya berperan untuk 
menekan pertumbuhan vegetatif tanaman tanpa mengurangi kualitas bunga yang dihasilkan, sehingga pemberian senyawa tersebut tidak berpengaruh terhadap diameter bunga. Menurut Mansuroglu et. al., (2009) respon diameter bunga terhadap Paklobutrazol pada tanaman cukup beragam bergantung pada jenis dan kultivar tanaman.

Tabel. 8 Pengaruh Dosis Paklobutrazol terhadap Diameter Bunga Primer Tanaman Bunga Matahari pada Umur 12 MST

\begin{tabular}{lc}
$\begin{array}{c}\text { Perlakuan } \\
\text { Paklobutrazol }\end{array}$ & $\begin{array}{c}\text { Diameter Bunga } \\
(\mathrm{cm})\end{array}$ \\
\hline $0 \mathrm{~mL} /$ polibag & $17,04 \mathrm{a}$ \\
\hline $50 \mathrm{~mL} /$ polibag & $18,25 \mathrm{a}$ \\
\hline $100 \mathrm{~mL} /$ polibag & $18,92 \mathrm{a}$ \\
\hline $150 \mathrm{~mL} /$ polibag & $\mathbf{1 9 , 1 3 ~ a}$ \\
\hline $200 \mathrm{~mL} /$ polibag & $17,46 \mathrm{a}$ \\
\hline $250 \mathrm{~mL} /$ polibag & $18,58 \mathrm{a}$ \\
\hline Keterangan: Angka-angka yang diikuti \\
huruf yang sama pada \\
kolom yang sama tidak \\
berbeda nyata berdasarkan \\
uji BNJ pada taraf 5\%
\end{tabular}

\section{Jumlah Biji dan Berat Biji}

Data yang pada Tabel 9. menyatakan bahwa pemberian Paklobutrazol 150 $\mathrm{mL} /$ polibag dapat meningkatkan produksi jumlah dan berat biji tertinggi. Tetapi di atas dosis tersebut dapat menurunkan produksi tanaman bunga matahari. Hal ini sesuai dengan hasil penelitian Junior et al. (2016) bahwa aplikasi Paklobutrazol pada biji dapat mengingkatkan hasil (jumlah dan berat biji) tanaman bunga. Paklobutrazol yang bersifat menghentikan tanaman sehingga cadangan karbohidrat menjadi lebih banyak sehingga memungkinkan tanaman untuk segera berbunga dan berbuah banyak (Isroi, 2017).
Tabel. 9 Pengaruh Dosis Paklobutrazol terhadap Jumlah Biji dan Berat Biji Tanaman Bunga Matahari

\begin{tabular}{ccc}
\hline $\begin{array}{c}\text { Perlakuan } \\
\text { Paklobutrazol }\end{array}$ & $\begin{array}{c}\text { Jumlah } \\
\text { Biji } \\
\text { (buah) }\end{array}$ & $\begin{array}{c}\text { Berat } \\
\text { Biji } \\
\text { (gram) }\end{array}$ \\
\hline $0 \mathrm{~mL} /$ polibag & $545 \mathrm{a}$ & $19,84 \mathrm{a}$ \\
\hline $50 \mathrm{~mL} /$ polibag & $682,5 \mathrm{a}$ & $28,82 \mathrm{a}$ \\
\hline $100 \mathrm{~mL} /$ polibag & $668,67 \mathrm{a}$ & $28,11 \mathrm{a}$ \\
\hline $150 \mathrm{~mL} /$ polibag & $\mathbf{7 5 9 , 7 5}$ a & $\mathbf{3 2 , 1 3 ~ a}$ \\
\hline $200 \mathrm{~mL} /$ polibag & $444,33 \mathrm{a}$ & $16,31 \mathrm{a}$ \\
\hline $250 \mathrm{~mL} /$ polibag & 615,33 a & $23,62 \mathrm{a}$ \\
\hline Keterangan: Angka-angka yang diikuti \\
huruf yang sama pada \\
kolom yang sama tidak \\
berbeda nyata berdasarkan \\
uji BNJ pada taraf 5\%
\end{tabular}

\section{SIMPULAN}

Paklobutrazol dengan berbagai dosis memberikan pengaruh yang sangat nyata saat tanaman berumur 6-11 MST dalam menghambat pertumbuhan tinggi tanaman bung matahari tetapi tidak berpengaruh nyata terhadap pengamatan lainnya. Penggunaan dosis Paklobutrazol yang berpengaruh untuk menekan pertumbuhan tinggi tanaman bunga matahari adalah $250 \mathrm{~mL} /$ polibag.

\section{DAFTAR PUSTAKA}

Badan Meteorologi, Klimatologi dan Geofisika. 2019. Data Iklim Bulan Februari - Juni. Tangerang Selatan.

Chaney, E.R., 2004. Paclobutrazol: More than just a Growth Retardant. Proceedings of the Pro-Hort Conference. Department of Forestry and Natural Resources. Purdue University. Peoria. Illinois

Dinas Pertanian Tanaman Pangan. 2014. Pengembangan Tanaman Hias. Dinas Pertanian Tanaman Pangan. Sumatera Barat

FAO. 2018. Production Statistics, Food and Agriculture Organization of the United Yr' Nations, http://www.fao.org (diakses pada 13 Okt, 2018). 
Ilham, K.D. 2018. Respon Pertumbuhan Bunga Matahari (Helianthus annuus L.) terhadap Pemberian Paklobutrazol pada Berbagai Konsentrasi. Skripsi. Fakultas Pertanian. Universitas Muhammadiyah Jakarta.

Isroi. 2017. Hormon Paklobutrazol untuk Merangsang Bunga dan Buah. https://isroi.com/2017/03/23/hormonpaclobutrazol/ (diakses 1 Agustus 2019).

Mansuroglu, S., O. Karaguzel, V. Ortacesme and M.S. Sayan. 2009. Effect of Paclobutrazol on Flowering Leaf and Colour of Consolida orientalis. Pak. J. Bot.

Marshel, E. 2014. Pengaruh Waktu Pemberian dan Konsentrasi Paclobutrazol Terhadap Pertumbuhan Bunga Matahari (Helianthus annuus L.). Skripsi. Fakultas Pertanian. Univeritas Sumatera Utara. Medan.

National Sunflower Association of Canada. The Sunflower Production Grade. 2011. http://www.canadasunflower.com (diakses pada 15 Des, 2018).

Novi dan Rizki. 2014. Induksi Pemekaran Bunga (anthesis) Tanaman Melati Putih (Jasminum sambac L. W. Ait) dengan Pemberian Paklobutrazol pada Beberapa Konsentrasi. Jurnal Pelangi Research of Education and Development.

Nugroho, P.T. 2012. Pengaruh Pacloburazol Dan Komposisi Larutan Pulshing Terhadap Kualitas Pasca Panen Bunga Matahari (Helianthus annuus L.) Sebagai Bunga Potong. Departemen Agronomi Dan Hortikultura Fakultas Pertanian. Institut Pertanian Bogor.
Rani, I. 2006. Pengendalian Pertumbuhan Tanaman Bunga Matahari (Helianthus annuus L.) dengan Aplikasi Paklobutrazol. Skripsi. Program Studi Hortikultura, Fakultas Pertanian, Institut Pertanian Bogor. Bogor.

Saini, S. dan Sharma, S. 2011. Helianthus Annuus (Asteracea). A Review. International Journal of Pharma Professional's Research.

Samanhudi. 2006. Studi Pembungaan dan Isolasi Gen Apetall pada Kakao (Theobroma cacao L.). Tesis. Institut Pertanian Bogor. Bogor.

Sandra, E. 2007. Membuat Anggrek Rajin Berbunga. Agro Media. Jakarta.

Santiasrini, R. 2009. Pengaruh Paklobutrazol terhadap Pertumbuhan dan Pembungaan Gloksinia (Sinningia speciosa Pink). Skripsi. Program Studi Hortikultura. Fakultas Petanian. Institut Pertanian Bogor. Bogor.

Suhadi, I., Nurhidayati, dan Sharon, A.B. 2017. Efektifitas Retardan Sintetik terhadap Pertumbuhan dan Masa Panjang Bunga Matahri (Helianthus annuus L.). Jurnal AGRIVOR. Vol 16. No.2.

Wahyurini, E. 2010. Stimulasi Pertumbuhan dan Perkembangan beberapa Kultivar Lili (Lilium longiflorum) dengan Aplikasi GA3 dan Paklobutrazol. Jurnal Agrivet.

Widaryanto,E, Baskara, M dan Suryanto, A. 2011. Aplikasi Paklobutrazol pada Tanaman Bunga Matahari (Helianthus annuus L. Cv. Teddy Bear) Sebagai Upaya Menciptakan Tanaman Hias Pot. Makalah. Fakultas Pertanian Universitas Brawijaya. Malang. 